\title{
Rape Culture and Epistemology
}

\author{
Bianca Crewe and Jonathan Jenkins Ichikawa ${ }^{1}$
}

for Jennifer Lackey (ed.), Applied Epistemology, Oxford University Press penultimate draft: 18 Feb 2018

\section{Introduction}

This chapter concerns a question more pressing than we wish it were: how should institutions and individuals react to sexual assault allegations that haven't been established in legal settings? For example, if student A accuses student B of sexual assault, but doesn't make a report to law enforcement, what formal university responses might be appropriate? (Should $B$ be barred from campus parties? Or expelled? What kinds of accommodations to A are appropriate?)

In general, the question of what to do in a given circumstance has a lot to do with epistemology. The right action depends on the reasons one has available, and the availability of reasons is an epistemic matter. On one widespread approach, it's a matter of knowledge. ${ }^{2}$ If you know that a student is a rapist, you are in a very different practical situation than you're in if you don't.

One tempting idea about our central question is that institutions and individuals should be deferential to law enforcement, effectively outsourcing the epistemology to the criminal justice system. For example, this line of thought has it that a university should take care to be neutral as to the truth of any allegation, unless and until the law enforcement process delivers its verdict. If a student is convicted of sexual assault in a fair criminal trial, a university should treat it as settled that the student is guilty of sexual assault, and react accordingly. But unless and until that happens, the university should do nothing. ${ }^{3}$

\footnotetext{
${ }^{1}$ Authors contributed equally; names are listed alphabetically.

${ }^{2}$ Central views in this tradition include Hawthorne \& Stanley (2008), Fantl \& McGrath (2009), and Weatherson (2012). Ichikawa (2017), pp. 139-42 defends the centrality of knowledge in action in terms of reasons. We work in the knowledge framework in this paper, although much of what we want to say is translatable into competing frameworks relating between epistemology and action. For example, if one thinks that all of one's justified beliefs are among one's practical reasons, a central question will be whether, in the kinds of cases we will go on to discuss, one justifiably believes that a sexual assault occurred. The considerations regarding rape culture, skepticism, and status quo biases we'll go on to discuss seem equally applicable in that framework; the considerations regarding contextualism might or might not be similarly applicable. (Cohen (1999) and Wedgwood (2008) defend the context-sensitivity of justification ascriptions.) So while we are working within a particular, admittedly controversial, framework, we hope that the interest of our project will extend to theorists in competing traditions.

${ }^{3}$ There are stronger and weaker forms of deference one might adopt. One might defer to law enforcement only in those cases in which the matter is being adjudicated legally; but proponents of the deferential stance often hold that one should suspend judgment even if the question has never been legally adjudicated.
} 
We think such temptation to deference is a powerful social meme, although it does not tend to be endorsed explicitly by university officials. One simple reason for this is that in many jurisdictions, the law directly prohibits this kind of deference. Since 1980 in the United States, for example, Title IX has required universities to have sexual harassment and assault policies beyond simple reference to law enforcement, on the grounds that sexual violence is a kind of gender discrimination. ${ }^{4}$ In Canada, Ontario and British Columbia instituted mandatory sexual assault policies for universities in 2017.

When students report sexual assaults by university members to their universities, the allegations are typically investigated by a university process separate from law enforcement. If university investigatory committees conclude that the allegations are true, they may take actions on this basis-firing, expelling, or otherwise disciplining the person found to have committed assault, for example. One common complaint about this kind of action is that it is insufficiently deferential; it amounts to "taking the law into their own hands", or, in cases in which legal proceedings are initiated but no conviction is reached, "putting their judgment over the law". We think the temptation to deference is influential, even among university administrators; certainly it is influential among the wider population. (You can find expressions of this deferential attitude near the top of every list of comments on news articles about university sexual assault policies.)

We'll argue that this sort of deference is mistaken, for at least two kinds of reasons. One is that, as anti-rape activists have often emphasized, law enforcement procedures themselves are deeply flawed when it comes to their practice of dealing with sexual assault. Another has to do with the connections between knowledge and action, and between knowledge and knowledge ascriptions. We also think that these disparate considerations are more closely interconnected than it may at first appear.

We'll begin in $\S 1$ with a discussion of some of the challenges to adequate law enforcement response to sexual assault, including the operation of sometimes-transparent social and political factors that constitute rape culture. In $\S 2$ we begin to foreground more explicit epistemological questions, focusing on the interaction of rape culture with the epistemology of testimony. §§3-4 take up the relationship between epistemology, practical reasoning, and action, explaining how skeptical pressure motivates a conservatism that benefits the status quo. We'll introduce, in §5, contextualism about knowledge ascriptions as a solution to some of the challenges that have emerged, and offer a further criticism of many deferential stances; in $\S 6$ we'll show how many of the social and political challenges discussed early in the paper recur with respect to metasemantic considerations.

\section{§1 Rape Culture and Law Enforcement}

Epistemic deference to law enforcement makes sense only to the degree to which law enforcement's epistemic procedures are reliable. ${ }^{5}$ So the idea that institutions and individuals

\footnotetext{
${ }^{4}$ For some legal discussion see Curtis 2017 and Johnson 2017.

${ }^{5}$ There are also important non-epistemic grounds for not deferring to law enforcement. For example, one might have political motivations for questioning the legitimacy of police and legal systems as authorities
} 
should so defer rests on particular assumptions about the contexts in which sexual assault and assault allegations occur, and about the formal and informal channels of justice in place to deal with them. Articulating these assumptions, and clarifying certain relevant features of the social and political context, will allow us to show how they are bound up with harmful epistemic idealizations.

When institutions or individuals defer to the investigative and procedural standards of police and the law, this bespeaks a high degree of confidence in these standards and procedures. We think such confidence betrays an ignorance of the social and political context in which sexual assault occurs, in which victims testify about their experience (formally and informally), and in which individuals, institutions, police, and the law respond to said testimony. For example, cultural attitudes surrounding sexual assault, women's credibility, ${ }^{6}$ and of patriarchal and misogynist presumptions of access and entitlement to women's bodies are significant determinants in how juries rule in sexual assault cases. These issues also have a lot to do with whether or not sexual assault is ever disclosed or reported. ${ }^{7}$

These social and political factors are sometimes theorized as elements of rape culture-a cultural environment where sexual assault and sexualized violence is a normative or expected type of interaction. ${ }^{8}$ This account demands that analysis of sexualized violence (and dominant understandings thereof) occur with an eye to the cultural and political factors that entrench and reproduce it, including spurious beliefs about race, gender, and sexuality. Rape culture is therefore visible not only in the statistics of reported sexual assault, but also in the cultural discourse that produces these statistics and other undisclosed experiences, and conditions responses to allegations of sexual assault. ${ }^{9}$

Importantly, patriarchal and misogynist values work in tandem with many other oppressive hierarchical systems in producing the social conditions structuring rape culture. Colonialism, racism, homophobia, ableism, and classism produce populations who are often especially vulnerable to sexualized violence. For example, racist stereotypes and the structural oppression faced by women of colour work in tandem to render this demographic at high risk for sexual

and instruments of justice. One could, for example, explain politically motivated non-deference in terms of both the lack of reliability exhibited in the epistemic procedures of law enforcement as well as the historical and contemporary violence enacted by the state in the protection of certain interests. Though we lack the space to explore these reasons in-depth, we seem them as part of a continuum with the epistemic reasons we examine throughout.

${ }^{6}$ Women are not the only demographic who experience sexualized violence, but the cultural attitudes that produce such things involve an ideology that is deeply gendered. Here, we will speak of "women" not only as the demographic category that experiences the highest rates of sexual assault, but also as an ideological category with built-in patriarchal baggage that renders it particularly susceptible to some of the political and epistemic problems discussed here. In cases where non-women experience and disclose their experiences of sexual assault, the widespread association of their experiences with typically feminine ones (and the even scarcer hermeneutical resources available to them) constitutes part of the difficult social situation that they face, both in terms of disclosing and being believed.

${ }^{7}$ Anderson (2003), George et al (1992); Koss (1985); McAusland (1998).

${ }^{8}$ Brownmiller (1975), Hampton (1999).

${ }^{9}$ Buchwald et al (2005), Burt (1980). 
assault, and likely to experience difficulties in reporting their experiences. ${ }^{10}$ These vulnerabilities are compounded when, for example, the women in question are refugees, asylum seekers, or immigrants, ${ }^{11}$ if they do not have stable access to housing, ${ }^{12}$ or if they have disabilities. ${ }^{13}$

One reason we are less optimistic about the ability of the law to deal with infractions stemming from patriarchy and misogyny has to do with the political and ideological affiliations of legal systems themselves. We think deferential attitudes mistakenly assume that no such affiliations exist. This vision rests on an idealized (and often unarticulated) account of the relationship between law and the cultural context in which it is embedded-one which many critical legal theorists have sought to bring to light. They argue that, often, liberal democratic institutions not only permit but also conceal and reify the subordination of women under the guise of formal neutrality. In Towards a Feminist Theory of the State, Catherine MacKinnon suggests that inasmuch as the state and its institutions are constituted in a cultural context, they will tend to reflect that culture. This means that, for example, a patriarchal culture is apt to yield and mutually reinforce a patriarchal state. According to MacKinnon, "women are oppressed socially, prior to law, without express state acts, often in intimate contexts," 14 and therefore states and institutions that are committed to negative freedom and judicial neutrality-and that see themselves as socially transcendent rather than embedded-will not be able to address injustices that arise from this configuration.

Attempts are increasingly being made to update laws and procedures surrounding sexual assault - the criminalization of sexual assault within marriage, for example, ${ }^{15}$ or the slow phasing out of the requirement of corroboration of sexual assault by witnesses. ${ }^{16}$ Although these developments reflect important cultural milestones, and doubtless improve the lives of many, there is still ample evidence ${ }^{17}$ and theoretical work on the ways in which the law and rape culture continue to co-operate. This situation arises from, and is compounded by, abstractions in law and in our conceptual analysis.

Epistemologists, critical legal theorists, and other scholars are increasingly attentive to how power, ideology, and oppressive cultural conditions affect theorizing, and to how the idealizations they employ sometimes abstract away from highly relevant contextual factors. Charles Mills's work is a central case in point. In his work on ignorance and idealization in philosophical theorizing, Mills emphasizes the gap between oppressive social conditions and

\footnotetext{
${ }^{10}$ Foley et al (1995), Donovan and Williams (2002), George and Martínez (2016).

${ }^{11}$ Hynes and Lopes (2000), Ward and Vann (2002), Wenzel et al (2004).

${ }^{12}$ Kushel et al (2003), Tyler et al (2010).

${ }^{13}$ Khalifeh et al (2015), Basile (2015).

14 Mackinnon, 1989: 165.

${ }^{15}$ In Canada, in 1983 with the update of Bill C-127, and in 1993 in all fifty of the United States.

${ }^{16}$ In the 1980s and 1990s in North America. See Tang (1998).

${ }^{17}$ For example, in statistics on untested evidence kits and underreporting in the United States- see Ritter (2011) and Rennison (2002).
} 
theoretical idealizations, writing that "abstracting away from realities crucial to our comprehension of the actual workings of injustice in human interactions and social institutions"18 provides little practical directives for the achievement of social justice, and, moreover, often obscures the existence of the very conditions that exacerbate injustices-like, for example, sexism and racism. Ultimately, Mills argues that this precludes achievement of the ideal-asidealized model, leading to situations in which theoretical idealizations serve to bolster the social and political status quo, and are employed, at least in part, for this reason.

MacKinnon's work is focused on a similar gap: namely, the one assumed between the private and public sphere, and, more generally, between what is deemed to be amenable to politicization and legal treatment, and what is not. MacKinnon and Mills focus on political philosophy, but their arguments apply equally to theorizing in epistemology, as we will show.

\section{$\S 2$ Knowledge and Testimony}

Law is not the only domain implicated in this kind of deferral of epistemic responsibility: folkconceptions (and double-standards) regarding the relationship between knowledge and testimony are also significant. Our epistemic reactions to testimony are heavily influenced by many cultural and political factors. Often we take testimony as, for all relevant purposes, conclusive for its contents. If you tell your friends where you went for dinner last night, they will probably take that as settling the question, even if there is something riding on it-if it would settle a bet, for instance.

It is, of course, possible to raise skeptical challenges to such cases: you might be lying. In cases in which we are wholly reliant on someone's testimony, the possibility that they are not telling the truth does constitute a skeptical scenario-it's a way that things could be that your evidence doesn't, in some strict sense, rule out. ${ }^{19}$ But we do not always treat the possibility of skeptical scenarios as undermining knowledge. In at least a wide variety of cases, our orientation toward testimony is a non-skeptical one: when someone tells us that $P$, we end up justified in believing that $P$. And ordinarily, if the speaker knows that $P$ and tells us that $P$, we end up ourselves knowing that $P$. That testimonial knowledge is common is both commonsense and philosophical orthodoxy. ${ }^{20}$

But we do not always take this kind of stance. Sometimes we interrogate testimony; sometimes we explain it away or demand proof. As much recent literature in both social psychology ${ }^{21}$ and epistemic injustice ${ }^{22}$ has shown, social and cultural factors influence the degree to which testimony is considered credible. The identity of both speaker and hearer, as well as the content being conveyed, influence the reception of testimony at the individual and broader cultural level.

\footnotetext{
${ }^{18}$ Mills (2005), p. 170.

${ }^{19}$ Lewis (1996), p. 553, lays out this way of thinking of skeptical scenarios.

${ }^{20}$ See e.g. Lackey (2008) or Adler (2015) for the philosophical canon.

${ }^{21}$ Frohmann, (1991); Mack, (1993); Mulder et al (1996); George et al (2016), Snyder et al (1977).

${ }^{22}$ Alcoff (2000); Jones (2002); Fricker (2007).
} 
Testimony that conveys a personal experience of sexual assault-especially in cases in which no one other than those involved in the interaction have firsthand knowledge of what occurredis often met with skepticism. In other words, a different epistemic standard is employed in these cases that is not present in the reception of other kinds of testimony.

Furthermore, the determination of whether or not the testimony of the individual alleging assault counts as knowledge is frequently cast in terms of measuring the reliability of two people against each other, without regard for important contextual features. This is a mistake, because some of those contextual features might incline members of the community, juries, and police to assume that one individual is much more reliable than the other, for reasons having to do with stereotypes and structural power. This is visible in what, in highly publicized controversies regarding sexual assault, is submitted as evidence that might decrease the reliability of the individual who is testifying that they were assaulted: their past sexual behaviour, their choice of clothing, their friends, their hobbies, etc.

Leigh Gilmore addresses this in her discussion of Anita Hill's testimony in the Clarence Thomas confirmation hearings:

Common notions like "Nobody knows what really happened" and "It's a case of he said/she said" deflect inquiry into what we might come to know and even what we already do know. Moreover, they participate in narrowing attention to the immediate time frame of crisis or scandal, restricting the frame temporally, and ensuring that no adequate context for understanding will emerge. For these reasons, Toni Morrison's comment on the hearing provides pivotal guidance: 'For insight into the complicated and complicating events that the confirmation of Clarence Thomas became, one needs perspective, not attitudes; contexts, not anecdotes; analyses, not postures. For any kind of lasting illumination, the focus must be on the history routinely ignored or played down or unknown. ${ }^{23}$

When individuals testify that they were sexually assaulted, their testimony is often considered to be less reliable than most testimony. It is often suggested that they are either lying-out of animus, or to seek attention, or because the 'survivor' identity is socially valuable-or deluded. Psychological discourse surrounding the harms of sexual assault often unwittingly contribute to rendering those who testify about their experience unreliable in the eyes of their audience. For example, in her book on the politics of sexualized violence, Alison Healicon notes that therapeutic articulations of the category of "rape victim" inhibit the effective communication of the experience, as individuals belonging to this category are understood to have a damaged grasp on reality. ${ }^{24} \mathrm{~A}$ "credibility conundrum" ensues ${ }^{25}$ : if, according to the available hermeneutics, the trauma of sexual assault damages a potential testifier specifically in terms of their capacities qua testifiers, then it will be impossible for their testimony to convey knowledge.

\footnotetext{
${ }^{23}$ Gilmore (2017), p. 57, citing Morrison (1992), p. x.

${ }^{24}$ Healicon (2016).

25 Jordan (2004).
} 
These assumptions and idealizations constitute a part of rape culture, and are invoked strategically to further entrench that culture. However, they do not necessarily arise out of the illwill of particular individuals or communities. Following Miranda Fricker's (2007) Foucauldian account of power in Epistemic Injustice, we take it that the lack of available hermeneutical resources for the communication and uptake of sexual assault narratives are a collective and structural problem, and are not necessarily withheld by particular individuals. Part of our aim in this chapter is to render visible the biases and automatic socio-political alignments embedded in fundamental epistemological concepts and assumptions.

In sum, rape culture has acute epistemic effects. It conditions the reception of testimony that alleges the occurrence of a sexual assault and restricts the hermeneutical resources that marginalized individuals can draw on to communicate their experience. The results of this are visible in the difference between idealized notions of how culpability, evidence, and knowledge are determined in cases where sexual assault is alleged, and what actually tends to occur. Many social scientists have studied what happens when individuals disclose that they have been sexually assaulted, in a variety of informal or institutional settings. By and large, those who seek to communicate their experience of sexual assault tend to suffer serious social and emotional costs for it. ${ }^{26}$ It's also important to note that the belief that there are hermeneutical and legal resources available to address such injustices are held much more readily by privileged groups and individuals: in a 1992 study on the disclosure of sexual assault, Gail Elizabeth Wyatt found white women far more likely to disclose their assaults than Black women, who "do not anticipate that they will be protected by traditional authorities and institutions." 27 Furthermore, because the reasons that some individuals or communities might be adverse to reporting to legal or penal authorities are often not broadly understood in dominant culture, failure to report is often construed as indicative of the weakness of a case and the perceived non-credibility of the person in question, rather than institutionalized racism, classism, sexism, ableism, etc.

The assumption that the testimony of people who claim to have been sexually assaulted is unreliable is poorly supported by the available evidence, as in fact false allegations of sexual assault are exceedingly rare. ${ }^{28}$ Of course, it is possible to find examples of false assault allegations. However, as in the more general examples discussed above, this does not undermine the general reliability of such reports. Indeed, it is essential to the epistemology of testimony generally that although sometimes testimony is misleading, it typically issues into knowledge. Reliability needn't be perfect reliability. But, as we have seen, the fact that sexual assault narratives are often quite trustworthy does not mean that they are, in fact, trusted.

\footnotetext{
${ }^{26}$ Davis et al. (1991); Golding et al. (1989); Ullman (2000); Ahrens (2006); Dworkin (2016); Wyatt (1992).

${ }^{27}$ Wyatt, 1992: 86.

${ }^{28}$ Lisak et al, (2010).
} 


\section{$\S 3$ Knowledge and Action}

As alluded to in the Introduction, there are important connections between epistemology and practical decision-making. A prerequisite to knowing what to do is knowing how things are. One way to encode that relationship is via a straightforward relationship between knowledge and reasons for action, according to which one's reasons constitute all and only that which one knows. ${ }^{29}$ On this framework, to know something is to have it conclusively settled-or at least, conclusively enough for one's practical purposes. If you know that $P$, you don't have to worry about whether not- $P$. Conversely, if uncertainty about $P$ renders the possibility of not- $P$ a serious practical consideration, you do not know that $P$.

The knowledge-reasons principle explains why skepticism and inaction are so closely connected. It explains, for example, why someone concerned about the possibility that an accused rapist is innocent will face pressure to deny knowledge of his guilt. "I know that he is guilty, but we shouldn't punish him because of the chance that he is innocent" is a contradiction.

The knowledge-reasons principle says that if something is known, it's available as a reason. If something is not known, then it implies that it's not a reason. ${ }^{30}$ This points to a normative complication of our discussion above. We have argued that unwarranted doubt, a manifestation of a pervasive rape culture, tends to attach to testimony about sexual assault; this often leads to inaction in a way that we consider an important mistake. But note that if one has doubt-even unwarranted patriarchal doubt-one may eo ipso fail to know. And this, given the knowledgereasons principle, implies that one lacks reason to act.

Jennifer Nagel's work on "epistemic anxiety" offers an example of how these ideas might interact. Nagel characterizes epistemic anxiety as a kind of feeling of uncertainty; when one is epistemically anxious, one doesn't consider the question to be settled. It is possible to have epistemic anxiety even when one's evidence is conclusive; having conclusive evidence and feeling as if one has conclusive evidence are different states. Epistemic anxiety, Nagel says, is inconsistent with knowledge because it is inconsistent with (outright) belief, which is itself necessary for knowledge. ${ }^{31}$

Epistemic anxiety is not automatically rational. If one is epistemically anxious, one may be accurately reflecting the weakness in one's epistemic position, but one might be experiencing

\footnotetext{
${ }^{29}$ The philosophical literature on reasons is vast, and complicated by diverse terminological choices. Ichikawa (2017), pp. 140-1 articulates a version of the approach we are using here, and situates it into broader discussions of 'internal' and 'external' reasons, and 'possessed' and 'unpossessed' reasons, and 'reasons' and rationalizing action.

${ }^{30}$ We recognize that this is a controversial commitment (though, as the previous footnote suggests, identifying just which views conflict with what is not straightforward, due to diverse terminological choices). The broader point is uncontroversial: there is a substantial connection between epistemology and appropriate action. The knowledge-reasons principle is one way of articulating it. As we said at the start, we expect that our central points are translatable into other frameworks.

${ }^{31}$ See e.g. Nagel (2010). Note that the 'belief' condition in the classical 'justified true belief' theory of knowledge stood for a kind of full commitment, similar to certainty or being sure. Gettier (1963). See Ichikawa (2017), pp. 224-6 for discussion.
} 
unwarranted doubt. Suppose someone doesn't know that a sexual assault has occurred because of epistemic anxiety. The knowledge-reasons principle says the fact of the sexual assault is not among their reasons; it's easy to argue they don't have sufficient reason to act. Does this vindicate a deferential response?

There are two strategies available to undercut this suggestion. One is to argue that epistemic rationality affirmatively requires belief in the cases in question. One ought not be epistemically anxious, because doing so is epistemically prohibited under the circumstances. ${ }^{32}$ On such a picture, unwarranted doubt cannot render someone's inaction epistemically faultless.

However, many epistemologists are skeptical of "positive" epistemic norms, and therefore do not take failure to believe something that one could have known to be an epistemic failure. ${ }^{33}$ Theorists of this stripe hold that epistemology is only in the business of identifying beliefs it's epistemically permissible to hold, but that there are no genuine positive epistemic norms. In our view, this tradition gives an unwarranted privileged place to skepticism. It holds that skepticism is always epistemically permissible.

But even theorists who limit epistemic normativity to prohibitions of belief typically allow that other sources of normativity—moral and pragmatic norms, for example—can interact with epistemic norms to generate obligations to believe. ${ }^{34}$ They insist that skepticism is epistemically permissible, but are open to the idea that positive moral or pragmatic norms interact with negative epistemic ones to require belief.

Whether or not one accepts positive epistemic norms, then, there is room to say that in some cases of epistemic anxiety regarding sexual assault testimony, one ought not have that anxiety, and one ought to believe the allegations. Skepticism is a mistake of some kind. As we have seen, skepticism often works in tandem with oppressive social conditions to discredit the knowledge claims of marginalized individuals and groups.

Our own sympathies are in favour of positive epistemic norms; we think that in these cases, failure to believe is as much an epistemic error as is believing something that isn't warranted. Undue epistemic anxiety is therefore on our view an epistemic error, in addition to being (in this case) a moral error. But whether or not one agrees with us about positive epistemic norms, one can agree that one should know.

\footnotetext{
${ }^{32}$ See e.g. Ichikawa and Jarvis (forthcoming) for an application of this line of thought in other kinds of cases.

${ }^{33}$ See e.g. Nelson (2010) and Littlejohn (2012), p. 47.

${ }^{34}$ For example, Nelson (2010) pp. 92-3 and Littlejohn (2012), p. 48 both allow that nonepistemic goals interact with epistemic restrictions on permissible belief to allow for hybrid obligations to believe.
} 


\section{§4 Pragmatic Encroachment and Epistemic Idealizations}

So far we have pointed to some reasons for concern about the uptake of sexual assault allegations - their reception is processed in an oppressive political and cultural context, where motivated doubt is a significant possibility. One might accept this much, however, and deny that such doubt is mistaken. Maybe the natural tendency towards epistemic anxiety, in the face of sexual assault allegations, is appropriate and justified, and deference to the legal system is the most appropriate cautious response.

There is a tendency towards skepticism when the perceived importance of a question is high. One way to motivate the kind of skepticism and deference we are discussing, then, is to emphasize the high practical stakes involved in responding to sexual assault allegations. For example, a person might in good faith believe that the seriousness of sexual assault allegations indicate that they are better handled in a legal setting. We have argued that this faith is often misplaced: harmful idealizations obscure the relationship between law and culture, and these idealizations are apt to reproduce oppressive conditions under the guise of formal neutrality.

Skeptical or deferential stances towards sexual assault allegations might also be motivated by the assumption that sexual assault is a "private" matter. However, the distinction between "public" and "private" is itself often mobilized in service of maintaining an oppressive status quo. For example, in The Sexual Contract, Carole Pateman argues that the traditional liberal distinction between the public and private sphere often situated women in the latter.

Furthermore, this tradition assumes the private sphere to be outside the scope of legal or political recourse, with the effect that violence or unequal power relations in this sphere are naturalized and obscured. ${ }^{35}$

In discussions of the high stakes surrounding sexual assault allegations, it is also common to emphasize the seriousness of the consequences for those who have been accused. This in effect emphasizes the risked harm of a false finding of responsibility. Perhaps, in the face of risks such as these, it takes a stronger evidential situation to count as knowing. This, broadly speaking, is the thought behind so-called 'pragmatic encroachment' in epistemology. ${ }^{36}$ Pragmatic encroachment theorists hold that knowledge doesn't just depend on "truth-relevant" features like one's evidential situation, but also on practical considerations like how high the stakes are. In particular, the higher the stakes, the more it takes to know. ${ }^{37}$

Applied to the present discussion, the pragmatic encroachment strategy might suggest that the gravity of the accusation, and its social and practical costs, are enough to raise the bar for knowledge. It's harder to know about sexual assault via testimony than it is to know other things,

\footnotetext{
${ }^{35}$ Pateman, 1988.

${ }^{36}$ The term was introduced by Jon Kvanvig in a "Certain Doubts" blog post in 2004.

${ }^{37}$ Central defenders of pragmatic encroachment include Stanley (2004), Fantl \& McGrath (2009), and Weatherson (2012).. See Weatherson (2017) for a sympathetic contemporary overview of the view.
} 
because the stakes are higher for beliefs about sexual assault. This strategy could explain institutional reluctance to take action against individuals accused of sexual assault: the costs of being wrong are just so high.

We are pessimistic about justifying this kind of reticence to believe via pragmatic encroachment. The explanation sketched assumes certain perspectives that should not be taken for granted. In particular, it emphasizes the risks and costs to the person accused of sexual assault, and ignores those for the person who testifies that they were assaulted.

In other words, it is important to note that what one considers to be a high-stakes situation (and the perspective from which stakes are analyzed) is itself conditioned by ethical and epistemic factors flowing from the political and ideological context. It is, for example, revealing of our cultural and political commitments that the framing of sexual assault controversies and trials often highlight the harms men and boys will experience as a result of being accused or found guilty of sexually assaulting someone. Kate Manne has labelled this phenomenon "himpathy". ${ }^{38}$ Likewise, the preoccupation with the potential for false accusations (especially given their infrequent occurrence) demonstrates that the one group's potential harms far outweigh the potential harms to another group in the cultural consciousness. Such considerations (and rape culture more generally) must be brought to bear when theorizing pragmatic encroachment in the context of responding to sexual assault allegations.

Pragmatic encroachment is motivated by a kind of risk-aversion. The implicit model is one that treats suspension of judgment as the default - to make a judgment is to undergo the risk of being wrong. Even if the pragmatic encroachment model explicitly recommends further investigation rather than the suspension of judgment, we take it that attention to the non-ideal and socially-embedded contexts of "high-stakes" epistemic situations might in fact reveal that skepticism and the felt need for further investigation are very closely connected. Indeed, their effects are identical, especially in cases in which one's own investigatory capacities are limited and the very meaning of "investigation" is steeped in oppressive assumptions.

In addition to motivating skeptical or deferential positions, the public/private divide also affects how harms and stakes are characterized. On the pragmatic encroachment mode, these characterizations are often dependant on longstanding cultural beliefs about sexual assault as a "private" matter implicating only the accuser and the accused. This stance limits the extent to which rape culture can be articulated as a harm at a collective or societal level, or indeed whether sexual assault can be understood in terms of pernicious cultural discourse rather than the mere ill-will or criminality of individual perpetrators. This stance also limits the extent to which communities and institutions can be held accountable for preventing sexual assault: doing nothing, whether under the guise of searching for further evidence or deferring to law enforcement, often implicitly condones the behaviour of those who perpetrate sexualized violence.

The problems with the pragmatic encroachment model are also related to our discussion of negative and positive epistemic norms in $\S 3$. Ultimately, the idea that suspending judgment is

${ }^{38}$ Manne (2018), pp. 196-201. 
the way to "play it safe" ignores the potential risk of failing to acquire available knowledge; moreover, following the injunction to "seek out further evidence" can, via selective investigation, provide further opportunities for one's inquiry to tilt in favour of confirming certain (patriarchal, etc.) starting points. ${ }^{39}$ It assumes, in effect, that the status quo-with the subject declining to form a belief on the matter-is normatively acceptable. But failure to form available knowledge can be costly and harmful. This is true in general, but especially obvious in the case of testimony of sexual assault.

Moreover, without an adequate understanding of how knowledge attributions are affected by rape culture, the resultant harms will be made invisible and further entrenched. This is because epistemic idealizations of the kind Mills discusses work in tandem with a strong bias towards the status quo, both in epistemology and in broader society. If pragmatic encroachment is understood in terms of some putatively "objective" standard of what counts as a high-stakes situation, it is likely that the perspective of socially dominant groups and individuals will be the yardsticks we employ, precisely because their perspectives are taken to be neutral. MacKinnon's work on the character of law in a patriarchal society, and Mills's account of ideologically-motivated idealizations are both intimately tied to this point. In effect, they caution that we must be wary of taking as neutral what is in fact ideologically loaded.

Some of the intuitions that are cited to motivate pragmatic encroachment in cases like these are susceptible of alternate explanations along these lines. A general tendency to favour the status quo-reinforced by the cultural elements it favours-is part of the story. ${ }^{40} \mathrm{~A}$ self-serving bias is surely another. It is disruptive to believe a sexual assault allegation-especially if it is against someone with whom one has any kind of significant relationship. A friend of one of the authors has recounted a story of discussing her sexual assault with the woman married to her assailant. In declining to listen, the wife explicitly cited the cost that believing would bring. "If it's as bad as you say," she told her, "believing it would destroy my marriage". Here, of course, she is citing the high cost of believing even if it's true, so the pragmatic encroachment mold doesn't fit in the usual way. But given the high cost of belief in general in cases like these, it's not difficult to imagine a kind of motivated invocation of the high cost of being wrong. It's easier to do nothing (viz, suspend judgment) and rationalize it via pragmatic encroachment. ${ }^{41}$

Transparency regarding how cultural and ideological commitments structure our inquiry is the first step to a version of philosophy that addresses oppression. Explaining the phenomena

\footnotetext{
${ }^{39}$ Compare the parallel point about scientific evidence in Levy (2017).

${ }^{40}$ Hundleby (2016) suggests we teach a "status quo bias" alongside the more canonical formal and informal fallacies.

${ }^{41}$ Charles Mills develops a similar idea in his work on ignorance. In The Racial Contract, he theorizes that the psychic and moral conditions that made possible slavery, colonization, and the continued structural privileging of whiteness involve the conceptual erasure of the personhood, property, and communities of racialized peoples. In the cases Mills considers in The Racial Contract, as in the example of believing disruptive testimony regarding sexual assault, self-transparency and a genuine commitment to understanding social realities would interfere with the positive self-conception of individuals and communities in privileged epistemic and social positions. As Mills puts it, these epistemologies of ignorance operate as a "pattern of localized and global cognitive dysfunctions," though they are "psychologically and socially functional." (Mills, 1997: 18).
} 
we've been investigating in terms of pragmatic encroachment must address the value-laden assumptions structuring that explanation. A commitment to a particular perspective (one that is automatically privileged in a rape culture) goes into the appeal to pragmatic encroachment to explain why knowledge cannot be conveyed in the cases we're considering here, and to fail to render this explicit as a commitment stemming from the social context of knowledge is problematic for ethical and epistemic reasons.

The project of rendering political commitments and the ideological context of knowledge explicit can also be seen as arising within feminist standpoint theory, especially with regard to the claim that the epistemic privilege of marginalized communities arises from their understanding of this context. For example, standpoint theory takes the occupation of a marginalized social location to enhance understandings of the workings of power, as marginalized people must negotiate both their own environments, where power and oppression are necessarily confronted, and the environments of the socially dominant, who have the privilege of remaining ignorant about the many of the features of their social world. ${ }^{42}$ It is the juxtapositioning of these environments that creates, for marginalized knowers, a sense that dominant accounts of the world are decidedly non-neutral and value-laden.

When considering pragmatic encroachment, the workings of the legal system, and testimony as applied to sexual assault, scholarship on epistemic privilege, motivated ignorance, and idealization all help to draw out why the foundations from which we reason often have invisible political and social implications. As Adrienne Rich notes, in a context that privileges and universalizes the experience of dominant groups (in this case, men), "objectivity has been little more than male subjectivity." ${ }^{43}$ Furthermore, values and political commitments are often only visible as such when they are different from the norm. We will expand upon this status quo bias, and related ideologically-motivated skepticism, in what follows.

\section{$\S 5$ Contextualism and Knowledge without Courtroom Knowledge}

We turn now to another aspect of the problem with excessive deference to law enforcement, declining to act on the grounds that guilt hasn't been proven in a legal setting. In a just and equitable criminal system, defendants are considered innocent in light of the law unless and until they are proven guilty. An inevitable consequence of any such system is that some genuinely guilty offenders will be acquitted, because, although they are guilty, they haven't been proven to be so. This is widely thought justified on the grounds that it is better for guilty people to walk free than it is for innocent people to be wrongly incarcerated. We accept these tenets of liberal democracy.

\footnotetext{
${ }^{42}$ Patricia Hill Collins theorizes this epistemic position in terms of the "insider-outsider," (1990); (1991), this line of thought also appears in Narayan (1988).

${ }^{43}$ Rich (1994), p. 3.
} 
Because of prosecutors' burden of proof, it obviously does not follow from the fact that someone has not been convicted of some criminal offense that they did not commit that crime. The phrase "innocent until proven guilty" doesn't mean that anyone literally is innocent. ${ }^{44}$ So much, we take it, is pretty obvious. After all, some people are guilty of crimes that no one ever found out about, and so were never prosecuted. But this is even true of people who have been acquitted, perhaps because the evidence against them was insufficient. Courts sometimes use the misnomer of "finding the defendant not guilty"-they might say more precisely that they did "not find the defendant guilty". Some defendants are guilty of the crimes of which they were acquitted. They are "innocent in the eyes of the law", but they are guilty.

According to the thought behind the deferential stance we critique, if there wasn't evidence sufficient for a criminal conviction, this typically demonstrates that we can never know whether someone is guilty of an offense, and so can't responsibly take any action in response. This is the thought behind the suggestion that, for example, if a sexual assault finding hasn't been established in court, it would be inappropriate to act on that accusation, because this would be putting our own judgment over that of the law.

For the reasons outlined in $\S 1$, we do not think that, when it comes to reacting to sexual assault, it is always wrong to put one's own judgment over that of the law. As enforced, the law is deeply flawed in many ways, including systematic ones. But we also think it's a mistake to suppose that in general, acting on one's own sexual assault finding, when there is insufficient evidence for criminal remedies, even amounts to putting one's own judgment over that of the law.

Suppose a sexual assault allegation is found insufficiently well-supported to justify legal remedy. From this it is very natural to infer that the evidence available was insufficient for knowledge that the assault occurred. If we assume that a university fact-finding procedure has access to the same body of evidence as law enforcement, then university fact-finders don't have evidence sufficient for knowledge either. So they too ought not to act on the allegation.

One way to resist the argument is to deny the link between knowledge and actionability. Another, discussed in $\S 4$, is to invoke pragmatic encroachment, suggesting that knowledge is possible only in the lower-stakes scenario, perhaps holding that the stakes of university findings, while serious, are not so weighty as those involved in legal decisions about whether someone ought to be convicted of a crime. We focus now on a different avenue of resistance: the contextualist one.

Contextualism about knowledge ascriptions is the view that sentences containing "knows" are context-sensitive. Like indexicals ("l", "now", "that"), gradable adjectives ("humid", "skillful", "feminist"), and other terms, "knows" is susceptible to diverse semantic implementations in different conversational contexts. ${ }^{45}$ For example, conversations that focus on skeptical ideas might tend to evoke higher standards for "knows". One influential motivation for contextualism is

\footnotetext{
${ }^{44}$ Article 11 of the Universal Declaration of Human Rights has it that "[e]veryone charged with a penal offence has the right to be presumed innocent until proved guilty according to law in a public trial".

${ }^{45}$ Influential early discussions of contextualism include Stine (1976), DeRose (2009), Lewis (1996), and Cohen (1999).
} 
its ability to explain patterns of intuition of this type. Perhaps in courtroom conversational contexts, high epistemic standards are in operation (perhaps because of the weighty practical matters at stake); consequently, "we cannot know what happened" might be true in the jurors' conversation. But in other contexts, even given the same evidence, when different actions are contemplated, "we know that a sexual assault occurred" might be true.

Contextualism is controversial, but in our view, it has much to commend it. ${ }^{46} \mathrm{~A}$ contextualist can tell a simple story about differential standards for action in criminal contexts and other contexts, such as university action: one can count as "knowing" that someone has committed a serious offense in a conversation about how the university ought to respond to it, without counting as "knowing" it in a conversation about whether the state ought to incarcerate the perpetrator. This framework straightforwardly invalidates the tempting argument that, since there wasn't evidence sufficient for criminal conviction, there's no way to know what happened, so it would be unwarranted to act on the basis of a mere allegation.

Here's an example of the kind of fallacious argument we have in mind. In 2016, after the University of British Columbia announced a plan for John Furlong to keynote a high-profile university event, activists protested the invitation, citing dozens of allegations of child abuse, including sexual abuse, by former students from the Canadian First Nations schools where Furlong taught in the 1970s. UBC briefly rescinded the invitation, but quickly reversed that decision. UBC President Santa Ono apologized to Furlong, writing that the withdrawal was made "without proper consideration of its potential impact on Mr. Furlong or his family". He reinstated the invitation, with this statement:

Notwithstanding what led to the decision to cancel Mr. Furlong's keynote address, I have made it my decision as president of the university to reverse course because it is simply the right thing to do. I decided this after better informing myself with the facts, including Mr. Furlong's stellar reputation in the fields of business, leadership and sport, the diverse views of our many stakeholders, and, as importantly, the judicial record. The British Columbia Civil and Supreme Courts have ruled in favour of Mr. Furlong in every matter that has come before them. The university had no basis to put its judgment above theirs. $^{47}$

Two things are notable about this passage. First, it is a clear example of the 'himpathy' phenomenon we discussed above, in this case reflecting settler-colonial priorities in addition to patriarchal ones. In this example, the interests of the accused are made salient, and those of the accusers are ignored. Second, it is an example of a fallacious argument from the lack of a legal finding of guilt to the conclusion that UBC lacks relevant knowledge to justify choosing a different speaker. The testimony of dozens of former students (some of which were given in

\footnotetext{
${ }^{46}$ DeRose (2009) and Ichikawa (2017) give extended sympathetic treatments of contextualism, including an emphasis on the connections between knowledge and action. Note also that even if contextualism is false in general, there is a strong case to be made that legal settings often invoke a distinctive sense of "knows", according to which one "knows" only that which one is permitted to take on board for the purpose of the legal discussion. Thanks to Alex Guerrero here.

${ }^{47}$ http://president.ubc.ca/featured/2017/01/09/ubc-reinstates-john-furlong-as-keynote-speaker/
} 
sworn affidavits) did, in our view, put UBC officials in a position to know that Furlong was not a good choice of someone to venerate.

This result, we think, is significant on its own-it refutes the deferential thought one hears every time one engages in public discourse about university sexual assault policies: "leave this criminal matter to law enforcement". Even if we set aside the many problems with the way law enforcement is practiced, because criminal contexts tend to evoke high epistemic standards, their conclusions do not always bear directly on what counts as "known" in other contexts, like university ones. Since we know many things that haven't been proven in court, ${ }^{48}$ the suggestion that we ought to act only on that which has been proven in court amounts to the suggestion that we ought to ignore many of the things we know. This is implausible in general; when it comes to e.g. ignoring the known fact that one's student is a rapist, it is negligently harmful.

Indeed, the argument is sometimes taken even further, to deny the appropriateness of individual actions in response to sexual assault allegations. Here is an anecdote illustrating the thought. ${ }^{49}$ We recently observed a discussion about a call for papers for a philosophy workshop dedicated to the work of Professor Vine, an influential philosopher who had been accused of sexual misconduct by multiple former students and employees. Another philosopher, Alvin, saw the call for papers, and suggested that, in light of serious and credible allegations against Vine, academics should not submit papers for this workshop. But Wade, another academic, took exception to Alvin's advice, arguing that the allegations against Vine, though serious, were unproven. Unless one had additional evidence, Wade said, beyond the detailed testimony that was then public, it would be irresponsible and unfair to Vine to take such an action as declining to submit to this workshop.

As our discussion above should make clear, we have several points of disagreement with Wade in this story. For one thing, a detailed public allegation by a credible witness, as there was in this case, is in fact excellent evidence of wrongdoing. For another, Wade's emphasis on the possible harms to Vine leave out a very important part of the story-Vine's accusers are harmed by discounting or setting aside their testimony; participating in the workshop despite their testimony would have contributed to the normalization of sexual assault in professional philosophy. Third, Wade's argument problematically assumes that suspending judgment on the allegations is the safe, "neutral" choice, and that taking a stance by refusing to submit to the workshop is an act of radicalism that requires a strong justification. But there is no clear reason why submitting to the workshop is the choice of default; indeed, in an intuitive sense, "not submitting a paper to a workshop" isn't an action at all-it's what one would do by default, absent some good enough reason to submit it. Assuming otherwise is an example of a harmful idealization in the sense of $\S 4$.

Fourth, however, this case is also an illustration of the possible contextualist fallacy. In a context of a jury deliberation, perhaps "we cannot know whether these allegations are true" is true,

\footnotetext{
${ }^{48}$ One might say: since we count as "knowing" many things relative to the standards appropriate for the actions we are contemplating.

${ }^{49}$ Because the conversation recounted took place in a private forum, we use pseudonyms here.
} 
because in that context, very strong epistemic standards are in effect; this simply does not imply that such sentences are true in more ordinary contexts, such as those operative in deciding whether to submit a paper to a workshop. To suppose otherwise is to assume that very high epistemic standards are always in effect, with the result that we "know" very little. Such skepticism is a recipe for inaction.

So far we have not said much about how it is that epistemic standards are generated, beyond a gesture at the idea that when the stakes are higher, there is a tendency to employ stronger standards for "knows". In $\S 6$, we foreground this question. We will suggest that there is an interesting connection between the ideas about rape culture mentioned in $\S 1$ and the metasemantic machinery of contextualism discussed in $\S 5$.

\section{§6 Epistemic Standards, Normativity, and Rape Culture}

Contextualism is a claim about the truth conditions of natural language sentences involving 'knows'. It is motivated, at least in part, by descriptive facts about the way 'knows' sentences are used, and it suggests that those uses amount to true ones. In this way, contextualism is conservative, rather than revolutionary. It is, in typical instances, motivated by a methodological commitment to preserving the truth of ordinary knowledge ascriptions. ${ }^{50}$

Nevertheless, we think it'd be a mistake to suppose that contextualism supports any kind of complacency about knowledge ascriptions. On the contrary, the normative issues we began with about rape culture and biases towards the status quo interact deeply with contextualism and knowledge ascriptions, pointing to an undertheorized avenue for political engagement. In this final section, we explore those connections. The result will be an example of the sort of complex relationship between feminist epistemology and contextualism gestured at in Brister (2017), p. 58.

We begin with two important metasemantic questions. First: can factors outside of individual speakers' knowledge and control influence the epistemic standards they employ? And second: are there substantive normative questions about what epistemic standards one ought to employ? If the answer to the first question is yes, then it will be relatively easy for speakers to make false 'knows' claims, due to an incorrect assessment of their own standards. If the answer to the second question is yes, then, even if someone is saying something that is true, it might be that they ought to be speaking in a context where that sentence wouldn't be true. Each of these possibilities corresponds to a kind of normative objectivity about knowledge ascriptions, pointing to ways in which whether one is proceeding properly may extend beyond the subject access.

An example of objectivity of the first sort has been defended in a series of papers by Christopher Gauker. ${ }^{51}$ Gauker's project emphasizes the mind-independence of contextual

\footnotetext{
${ }^{50}$ DeRose (2009) is particularly clear about this kind of motivation; see especially his pp. 56-9.

${ }^{51}$ See e.g. Gauker (2008) and Mion and Gauker (2017).
} 
parameters, holding that, for example, whether a skeptical possibility is relevant depends more on the features of the situation at issue than on the speaker's attention or intentions. On such a view, speakers might falsely believe that a certain skeptical worry is contextually relevant-this would lead to false 'knowledge' denials. For example, in a knowledge ascription involving testimony about sexual assault, one might hold that objective features of one's situation imply a less skeptical epistemic standard, even if the speaker thinks a more stringent standard is operative. If so, individuals may face significant challenges in recognizing their own contextual situations; if one is unaware of the operation of these tacit contextual standards, one may be a very poor judge of knowledge ascriptions. Improved self-awareness, including awareness of one's contextual situation, is crucial. ${ }^{52}$ This points to the structural nature of the problem: since rape culture isn't under the immediate control of the individuals negatively affected by it or perpetrating it, the development of alternative hermeneutical resources for understanding and responding to sexual assault must involve a collective cultural effort, as well as the cultivation of certain epistemic virtues sensitive to particularities of context. ${ }^{53}$

Even if one allows that speakers have considerable fiat over the relevant features of their conversational contexts, there is still room for a more objective assessment. Suppose for example that the context-sensitivity of 'knows' is largely a matter of something like David Lewis's "Rule of Attention", according to which whether an alternative is dependent on whether the speaker is thinking about it. ${ }^{54}$ As has often been observed, Lewis's is a skeptic-friendly version of contextualism: if one is thinking about a skeptical scenario, and a subject's evidence doesn't rule that scenario out, then in one's context, the subject can't "know" that the scenario doesn't obtain. For example, if a speaker is thinking about the possibility that a witness is lying, then, in the speaker's context, no one will count as "knowing" the fact testified unless their evidence is sufficient to rule out a lie. On such a picture, speakers will have considerable control over the relevant features of their conversational contexts; compared to Gauker's framework, we'd expect mistaken knowledge ascriptions to be rarer on a Lewisian story.

But this doesn't imply that there aren't substantive normative questions about knowledge ascriptions. Truth or falsity of utterances isn't the only thing we might be interested in evaluating. We may assume that subjects have the ability to implement whatever contextual parameters they like; that doesn't mean there aren't norms governing these conversational decisions.

For one example of the kind of view we are thinking of, consider Sarah Moss's (2018) discussion of belief in harmful stereotypes. Moss is interested in cases where statistical evidence seems to support a probabilistic claim that it'd be intuitively morally problematic to

\footnotetext{
${ }^{52}$ As a rough analogy, consider Miranda Fricker's discussion of hermeneutical marginalization. Some aspects of some people's experiences are particularly difficult some people to comprehend because they lack the necessary hermeneutical resources. This is not a failure that can be diagnosed 'from the inside'; there is no simple recipe for detecting and avoiding it. Instead, one must develop a disposition of openness to experiences that are difficult for one to understand, recognizing that one's hermeneutical resources are limited.

${ }^{53}$ This is one explanation for some of the value of consciousness-raising. See Kelland (2016).

${ }^{54}$ Lewis (1996), p. 559-60. The subject's attention is one of several factors that influence relevance, in Lewis's framework.
} 
accept. To take one of Moss's examples, suppose one knows on general statistical grounds that most of the women in a given office building are administrative assistants, and that one encounters a woman there, with no additional evidence relevant to her role. Moss wishes to deny that one can know on these grounds that she is probably an administrative assistant. To do this, she invokes a broadly Lewisian form of contextualism, along with what she calls the "Rule of Consideration". This is a moral norm to the effect that "in many situations where you are forming beliefs about a person, you morally should keep in mind the possibility that they might be an exception to statistical generalizations." ${ }^{55}$ The idea here is that one morally ought to be thinking about certain possibilities, such as the possibility that the woman one sees is a statistically unusual woman who is probably a manager, rather than an administrative assistant. And if one were thinking about such a possibility, it would count as relevant for the purpose of the knowledge ascription. If one flouts the Rule of Consideration, one might speak truly with an utterance ascribing "knows that she's probably an administrative assistant" to someone in this situation. But Moss's view is that one has a moral obligation not to flout the Rule of Consideration. If one ignores the possibility that this woman is exceptional, one has spoken truly, but behaved badly.

This isn't the venue to adjudicate the plausibility of Moss's particular suggestion; we mention it as a vivid example of the ways in which moral considerations and contextual parameters can interact. There can be questions about what kinds of epistemic standards are appropriate.

Moreover, most contextualists hold that speaking as if a given standard is in effect has a tendency of putting that standard into effect. ${ }^{56}$ So knowledge denials in debatable cases-such as testimony-will have a tendency of raising the standards for knowledge. An assertion to the effect that "there's no way to know what really happened" can, if left unchallenged, lead to a more skeptical context where that sentence is true. Given the connections between knowledge ascriptions and action, such skeptical standards can have dramatic sociopolitical effects.

For reasons much like these, Esa Diaz-Leon has recently suggested that, given contextualism, a knowledge ascription carries two important roles in a conversation. In addition to semantically expressing its content, it also conveys the pragmatic suggestion that the standard employed is the proper one. Diaz-Leon writes, about a disagreement between a Moorean who ascribes "knowledge" and a skeptic who denies "knowledge", that:

Moore and the skeptic (might) express compatible propositions at the semantic level, but they still express a genuine disagreement. In particular, their disagreement can be explained at the pragmatic level. That is, when the skeptic utters [a 'knowledge' denial], she is expressing the proposition that Moore does not satisfy certain (very high) standards of justification, whereas when Moore utters [a 'knowledge' ascription], he is expressing the proposition that he does satisfy certain lower standards of justification. These two propositions are compatible. But the skeptic is also conveying the information that "knows" should be used in a way so that one would count as knowing a proposition

\footnotetext{
${ }^{55}$ Moss (2018), §10.4.

56 Lewis (1979) is the locus classicus.
} 
only when one satisfies certain very high standards, whereas Moore is also conveying the information that "knows" should not be used in that way. ${ }^{57}$

Diaz-Leon's emphasis in her paper is to explain the sense of disagreement that persists in cases like these, where contextualism seems to allow that the speakers are asserting compatible truths. But her proposal here, with which we are sympathetic, offers an important framework for thinking about an additional political power of knowledge ascriptions, given contextualism. The flexibility of contextualism corresponds to a flexibility of which testimony to take seriously.

An extreme example will make the connection vivid. Imagine a community that systematically employs high standards when talking about what women do or do not "know" and whether one can "know" on the basis of women's testimony, and low standards when talking about the parallel issues for men. In this community, people will react to women's descriptions of their experiences with utterances like, "people sometimes misinterpret other people's actions, so although she thinks he was being sexist, she doesn't know it". But when men describe their experiences, skeptical possibilities don't tend to come to mind, so people say things like "he knows what happened because he saw it himself." And female testimony will be greeted with the skepticism that comes with high standards: "we can't know unless we have some way to make sure she isn't lying", with no similar skepticism about male testimony.

This is a thought experiment, though not, we think, a terribly far-fetched one. The point is to demonstrate that contextualism generates a dimension allowing the truth of utterances to come rather far apart from their normative aptness. Although there are many things deeply wrong with the misogynistic society posited, a tendency to make false knowledge ascriptions needn't be one of them. The corollary is: one can object to assertions that reflect and contribute to rape culture without insisting that the contents of the assertions are false. One way assertions can contribute to rape culture is by managing epistemic standards in a way friendly to perpetrators of sexual assault.

"He-said-she-said" discourse is a case in point. If a woman accuses a man of sexual assault, and he rebuts that there was sexual contact, but that it was consensual, this is literally a case in which "he said" one thing and "she said" something inconsistent. Pointing this out tends to have the conversational effect of inducing speakers to employ high epistemic standards, such that "we can't know what really happened" will come out true. But that doesn't mean we should modify the context in this way. If this is one of the many examples where "her" testimony is much more credible than "his", it may well be that lower standards are appropriate, such that we can "know" that misconduct occurred. (This will be particularly plausible when informal action is being contemplated-i.e., decisions about whom to invite to a party, or whether to submit to a conference. These actions indicate what is acceptable in the context of shared social life, and do not hinge on a particular definition of relevant communities (for example, the state) or of the standards of that community (for example, proof beyond a reasonable doubt).

57 Diaz-Leon (2017), p. 75. Diaz-Leon is applying to "knows" a strategy she attributes to Plunkett \& Sundell (2013), who make a similar suggestion about moral evaluative language. 
The ability to affect the conversational context in a particular way is a kind of social power. Not all parties to the disagreements Diaz-Leon describes are on equal footing. Like most social power, this ability is not distributed impartially; in a rape culture, those seeking to raise the standards governing sexual assault allegations will have the field tilted in their favour. So we agree with Evelyn Brister's (2009) suggestion that it is helpful and informative to look to contextualism through a feminist lens, with an eye towards the deployment of social power. Brister emphasizes that, in a contextualist framework, "skepticism is a kind of power grab that puts other epistemic agents on the defensive and at a disadvantage. While some might believe that knowledge is power, the skeptic recognizes denying knowledge is power." She continues:

Recognizing the power dynamics of skeptical arguments allows us to examine the interests that philosophical skepticism serves. To begin with, philosophical skepticism distrusts all knowledge claims and avoids falsehood at the cost of dismissing possible truths: this represents a deeply conservative attitude toward the production of knowledge. For this reason, skepticism poses a special danger to novel claims that may already face a higher burden of proof and where skeptical objections may then prove decisive. In this way philosophical skepticism can exacerbate existing conditions of epistemic unfairness. ${ }^{58}$

And:

The skeptic would deny a collective responsibility for coordinated inquiry-and since all the institutions of scientific investigation, justice, and political accountability depend on decision making guided by knowledge claims, the skeptic's change of context undercuts our ability to act on the basis of justified beliefs. ${ }^{59}$

We agree with both thoughts here. To Brister's observations, we add that real-world skepticism isn't a monolithic raising of standards, the way introductory epistemology courses sometimes imagine it is; it is a tool that is used selectively and strategically to promote entrenched interests.

So the flexibility of knowledge ascriptions, given contextualism, comes along with significant social power. The decision to employ some standards rather than others is a political one. It shouldn't be surprising, then, to suggest that this power tends to be wielded in a way that tends to protect the interests of the status quo. In general, social power tends to be used to reinforce itself. The case of contextualism is particularly interesting in this respect, due to its largely invisible operation. Notoriously, contextualism posits context-sensitivity in natural language about which many ordinary speakers are unaware. This is part of the reason why contextualism is a controversial thesis. Some epistemologists have rejected contextualism on the grounds that it is implausible that language could exhibit this kind of context-sensitivity without ordinary speakers' recognizing it. ${ }^{60}$ We are sanguine about this "semantic ignorance" problem; we see no

\footnotetext{
${ }^{58}$ Brister (2009), p. 682.

59 ibid p. 683.

${ }^{60}$ Schiffer 1996 was particularly influential along these lines. See also Hawthorne (2003), pp. 107-9 and Stanley (2005) pp. 115-20. Greenough and Kindermann (2017) give a contemporary overview of this kind of challenge, and offer a response on behalf of the contextualist.
} 
particular tension in the idea that natural language exhibits surprising features ordinary speakers may be confused about. What we'd like to emphasize is that this confusion contributes to speakers' ability to wield social power in an unreflective way.

If one is unaware of the choice point of selecting an epistemic standard in a given situation, one may employ various biases, under a misapprehension of objectivity. If, for example, one has a natural tendency to favour the testimony of the socially powerful over that of marginalized people, one might, in a way similar to the society in our thought experiment above, employ higher standards in some cases than others, without realizing it. We think there's good reason to suspect this is reasonably common. ${ }^{61}$

In The Epistemology of Resistance, José Medina (2013) argues that structural inequality distorts epistemic relations between privileged people and oppressed people, resulting in a "numbness" among the privileged to injustices against the oppressed. As a consequence, the default epistemic positions of privileged communities and individuals are often oppressive ones. Applying this to our investigations here means that even without overt sexist biases or outright ill-will, it is possible to make knowledge ascriptions in a way that maintains and supports rape culture, and does violence to those who are attempting to be heard. (Indeed, "possible" here is an understatement. It's what we should expect.)

As we have argued, putatively "neutral" responses like suspending judgment or "doing nothing" can themselves be substantive contributions to, and reflections of, rape culture. This is true both because it normalizes bad behaviour, contributing to the general idea that it is acceptable, and, given contextualism, because it amounts to accommodating harmful conversational contexts. Indeed, contextualism is valuable in part because of the way it deals with skepticism, but attention to the ways in which it can be used as a conservative force is crucial to applying contextualism in an anti-oppressive way. Transparency regarding when harmful conversational contexts are being activated is itself a significant achievement for social justice. Following feminist standpoint theorists, we think marginalized individuals are typically situated best to know when this is occurring.

Our project here has been in many ways a continuation of the critical work of feminist philosophers who argue that the "view from nowhere" is in fact often a view from a very particular and situated location. However, acknowledging how tendencies towards conservatism, risk aversion, and alignment with the status quo can have oppressive effects is not merely a critical endeavor. Indeed, though rape culture is a structural phenomenon, there are things that we can do collectively and as individuals to resist its negative epistemic effects. The implicit biases that motivate the reception of sexual assault narratives are not unchangeable. Moreover, we do hold people morally accountable for addressing such biases,

\footnotetext{
${ }^{61}$ This might be an alternate way of implementing some of Miranda Fricker's ideas about testimonial injustice. Testimonial injustice is a "credibility deficit owing to identity prejudice in the hearer" (Fricker 2007 , p. 28). A credibility deficit is naturally thought of as a lower-than-deserved confidence in one's credibility. An alternate proposal, inspired by our remarks above, might characterize the inappropriate invocation of high epistemic standards as a kind of credibility deficit. Perhaps one can commit an epistemic injustice, not by having too low an opinion of someone's credibility, but by setting too high a bar for accepting their word.
} 
as well as their active, motivated epistemic ignorance regarding certain politically loaded concepts or identities. ${ }^{62}$ Consciousness-raising is also invaluable as both a means of introducing new hermeneutical resources into the public eye, and a way for individuals to come to recognize their own contexts. Feminist theorizing of the second-wave-the heyday of consciousness-raising - tells us that "the personal is political." Accounting for this at the level of epistemic theory has been part of our project here. ${ }^{63}$

\section{References}

Adler, Jonathan, "Epistemological Problems of Testimony", The Stanford Encyclopedia of Philosophy (Summer 2015 Edition), Edward N. Zalta (ed.), URL = <https://plato.stanford.edu/archives/sum2015/entries/testimony-episprob/>.

Ahrens, Courtney E. (2006). "Being Silenced: The Impact of Negative Social Reactions on The Disclosure of Rape." American Journal of Community Psychology, 38(3-4), 263-74.

Anderson, Michelle (2003), "Prostitution and Trauma in U.S. Rape Law," Journal of Trauma Practice, 2 (3/4).

Basile, K. C., Breiding, M. J., \& Smith, S. G. (2016). "Disability and Risk of Recent Sexual Violence in the United States." American Journal of Public Health, 106(5), 928-933.

Brister, Evelyn (2009), "Feminist Epistemology, Contextualism, and Philosophical Skepticism", Metaphilosophy 40(5): 671-88.

Brister, Evelyn (2017), in Ichikawa (ed.), Routledge Handbook of Epistemic Contextualism, London: Taylor \& Francis 57-67.

Brownmiller, Susan (1975). Against Our Will: Men, Women, and Rape. New York: Penguin Books.

Brownstein, Michael and Saul, Jennifer (2012) Eds., Implicit Bias \& Philosophy, vol. 2: Moral Responsibility, Structural Injustice, and Ethics Oxford: Oxford University Press.

Buchwald, E., Fletcher, P., and Roth, M. (2005). Transforming a Rape Culture. Milkweed Editions.

\footnotetext{
${ }^{62}$ See, for example, Mills (2005) and (2007), Sullivan (2006), Holroyd (2012), and the first five chapters in Brownstein \& Saul (2016).

${ }^{63}$ We are grateful to Nate Bemis, Nathan Cockram, Annaleigh Curtis, Jeremy Dawson, Logan Fletcher, Jennifer Freyd, Sandy Goldberg, Jade Hadley, Cassie Herbert, Marc Hewitt, Carrie Jenkins, Glynnis Kirchmeier, Jennifer Lackey, Lauren Leydon-Hardy, Clayton Littlejohn, Lucia Lorenzi, Graham Moore, Carla Nappi, Phyllis Pearson, Kathryn Pogin, Alan Richardson, Kyle da Silva, Joe Slater, Chris Stephens, Rodrigo Valencia, Jordan Wadden, Nancy Wu, and Michel-Antoine Xhignesse, for discussion of drafts of this paper and for inspiration and discussion related to this material. We're especially grateful to Alex Guererro, who provided helpful and detailed comments on an early full draft.
} 
Burt M. (1980) "Cultural Myths and Supports for Rape", Journal of Personality and Social Psychology 38:217-30.

Cohen, Stewart (1999) "Contextualism, Skepticism, and the Structure of Reasons", Philosophical Perspectives 13, 57-89

Crouch, M. A, and Schwartzman, L. (2012). Special Issue on Gender, Implicit Bias, and Philosophical Methodology. Journal of Social Philosophy 43(3).

Curtis, Annaleigh," Due Process Demands As Propaganda: The Rhetoric of Title IX Opposition" (June 4, 2017). Yale Journal of Law and the Humanities, Vol. 29, 2017. Available at SSRN: https://ssrn.com/abstract=2980500

Davis R. C., Brickman E., and Baker T. (1991) "Supportive and Unsupportive Responses of Others to Rape Victims: Effects of Concurrent Victim Adjustment." American Journal of Community Psychology. 19:443-451.

DeRose, Keith (2009) The Case for Contextualism, Oxford: Oxford University Press.

Diaz-Leon, E. (2017) “Epistemic Contextualism and Conceptual Ethics”, in Ichikawa (ed.), Routledge Handbook of Epistemic Contextualism, London: Taylor \& Francis 71-80.

Donovan, R. and M. Williams, 2002, "Living at the Intersection: The Effects of Racism and Sexism on Black Rape Survivors", Women and Therapy, 25(3/4): 95-105.

Du Mont, J., K.L. Miller, and T.L. Myhr. "The Role of 'Real Rape' and 'Real Victim' Stereotypes in the Police Reporting Practices of Sexually Assaulted Women." Violence Against Women 9(4)(April 2003): 466-486.

Dworkin, Emily R. (2016) "Disclosing Sexual Assault Within Social Networks: A Mixed-Method Investigation." American Journal of Community Psychology. 57(1-2).

Fantl, Jeremy and McGrath, Matthew (2009) Knowledge in an Uncertain World, Oxford: Oxford University Press.

Foley, Linda A., Evancic, Christine, Karnik, Karnik, King, Janet, and Parks, Angela (1995) "Date Rape: Effects of Race of Assailant and Victim and Gender of Subjects on Perceptions", Journal of Black Psychology, 21(1): 6-18.

Fricker, Miranda (2007) Epistemic Injustice. Oxford: Oxford University Press.

Frohmann, Lisa. (1991) "Discrediting Victims' Allegations of Sexual Assault: Prosecutorial Accounts of Case Rejections." Social Problems 38, no. 2: 213-26.

Gauker, Christopher (2008) “Zero Tolerance for Pragmatics”, Synthese 165(3): 359-71.

Gauker, Christopher, and Mion, Giovanni (2017) "The Mind-Independence of Contexts for Knowledge Attributions", in Ichikawa (ed.), Routledge Handbook of Epistemic Contextualism, London: Taylor \& Francis 455-64. 
George L., Winfeld I., Blazer D. (1992) "Sociocultural Factors in Sexual Assault: Comparison of Two Representative Samples of Women.” Journal of Social Issues. 48:105-125.

George, William H., Martínez, Lorraine J. (2016) "Victim Blaming in Rape: Effects of Victim and Perpetrator Race, Type of Rape, and Participant Racism." Psychology of Women Quarterly. Vol. 26, Issue 2., 110-119.

Gettier, Edmund (1963) “Is Justified True Belief Knowledge?”, Analysis 23(6): 121-3.

Gilmore, Leigh (2017) Tainted Witness: Why We Doubt What Women Say About Their Lives, New York: Columbia University Press.

Greenough, Patrick and Kindermann, Dirk (2017) "The Semantic Error Problem for Epistemic Contextualism", in Ichikawa (ed.), Routledge Handbook of Epistemic Contextualism, London: Taylor \& Francis 305-20.

Golding J. M, Siegel J. M., Sorenson S. B., Burnam M. A., Stein J. A. (1989) "Social Support Sources Following Sexual Assault.” Journal of Community Psychology. 17:92-107.

Hampton, J., 1999, "Defining Wrong and Defining Rape", in A Most Detestable Crime: New Philosophical Essays on Rape, K. Burgess-Jackson (ed.), New York: Oxford University Press, pp. 118-156.

Hawthorne, John (2003) Knowledge and Lotteries Oxford: Oxford University Press.

Hawthorne, John and Stanley, Jason (2008) "Knowledge and Action", Journal of Philosophy 105(10):571-90.

Healicon, Alison (2016). The Politics of Sexual Violence: Rape, Identity, and Feminism. London: Palgrave Macmillan UK.

Hill Collins, Patricia (1990). Black Feminist Thought: Knowledge, Consciousness, and the Politics of Empowerment. New York: Routledge.

Hill Collins, Patricia (1991) "Learning from the Outsider Within," in Mary Margaret Fonow and Judith A. Cook, (eds.), Beyond Methodology: Feminist Scholarship as Lived Research (Bloomington IN: Indiana University Press) 35-39.

Holroyd, Jules (2012) "Responsibility for Implicit Bias", Journal of Social Philosophy 43(3): 205362.

Hundleby, Catherine E. (2016) "The Status Quo Fallacy: Implicit Bias and Fallacies of Argumentation", in M. Brownstein and J. Saul, eds., Implicit Bias \& Philosophy, vol. I: Metaphysics and Epistemology.

Hynes, M. and Lopes, C.B. (2000) "Sexual Violence Against Refugee Women", Journal of Womens Health \& Gender Based Medicine, 9(8): 819-23. 
Ichikawa, Jonathan Jenkins (2017) Contextualising Knowledge, Oxford: Oxford University Press.

Ichikawa, Jonathan Jenkins and Jarvis, Benjamin W. (forthcoming), "Hybrid Virtue Epistemology and the A Priori”, in Dylan Dodd and Elia Zardini (eds.) The A Priori: Its Significance, Grounds, and Extent, Oxford: Oxford University Press.

Johnson, Antuan M. (2017), "Title IX Narratives, Intersectionality, and Male-Biased Conceptions of Racism", 9 GEO. J. L. \& MOD. CRIT. RACE. PERSP. 57 (2017).

Jones, Karen (2002). "The Politics of Credibility," in Louise M. Antony and Charlotte E. Witt, (eds.) A Mind of One's Own: Feminist Essays on Reason and Objectivity, 2nd. Edn. Boulder, Colorado: Westview Press.

Kelland, L. (2016). "A Call to Arms: The Centrality of Feminist Consciousness-Raising SpeakOuts to the Recovery of Rape Survivors." Hypatia, (31)4.

Khalifeh, H. et al (2015). "Domestic and Sexual Violence Against Patients with Severe Mental Illness." Psychological Medicine, 45(4): 875-886.

Koss M. (1985). "The Hidden Rape Victim: Personality, Attitudinal, and Situational Characteristics" Psychology of Women Quarterly 9:193-212.

Kushel M, et al. (2003) "No Door to Lock: Victimization among Homeless and Marginally Housed Persons" Archives of Internal Medicine, (163)20: 2492-2499.

Lackey, Jennifer (2008) Learning from Words, Oxford: Oxford University Press.

Levy, Neil (2017) “Due Deference to Denialism: Explaining Ordinary People's Rejection of Established Scientific Findings", Synthese Online: https://doi.org/10.1007/s11229-017-1477$\mathrm{x}$

Lewis, David (1979) "Scorekeeping in a Language Game", Journal of Philosophical Logic $8(1): 339-59$.

Lewis, David (1996) "Elusive Knowledge”, Australasian Journal of Philosophy 74(4): 549-67.

Lisak, David, Lori Gardinier, Sarah C. Nicksa, and Ashley M. Cote. (2010) "False Allegations of Sexual Assualt: An Analysis of Ten Years of Reported Cases." Violence Against Women 16, no. 12:1318-1334.

Littlejohn, Clayton (2012) Justification and the Truth-Connection Cambridge: Cambridge University Press.

Mack, Kathy. (1993). "Continuing Barriers to Women's Credibility: A Feminist Perspective on the Proof Process." Criminal Law Forum, 4,(2): 327.

Mackinnon, Catherine (1989) Towards a Feminist Theory of the State, Cambridge, MA: Harvard University Press 
Manne, Kate (2018) Down Girl: The Logic of Misogyny, New York, Oxford University Press.

McAuslan, P. (1998). After Sexual Assault: The Relationship Between Women's Disclosure, the Reactions of Others, and Health. Dissertation Manuscript. Wayne State University, Detroit, MI.

Medina, José (2013) The Epistemology of Resistance: Gender and Racial Oppression, Epistemic Injustice, and Resistant Imaginations Oxford: Oxford University Press

Mills, Charles (1997) The Racial Contract. New York: Cornell University Press.

Mills, Charles (2005) “'Ideal Theory' as Ideology.” Hypatia. (20)3

Mills, Charles (2007). "White Ignorance." in Race and Epistemologies of Ignorance, Sullivan, S. and Tuana, N. (Eds.), Albany: SUNY Press.

Morrison, Toni (1992). "Introduction: Friday on the Potomac," in T. Morrison (ed.), Race-ing Justice, En-gendering Power: Essays on Anita Hill, Clarence Thomas, and the Construction of Social Reality, New York: Pantheon: vii-xxx.

Mulder, Marianne R. and Frans Willem Winkel (1996) 'Social Workers' and Police Officers' Perceptions of Victim Credibility: Perspective-Taking and the Impact of Extra-Evidential Factors," Psychology, Crime and Law 2(4): 307-319.

Moss, Sarah (2018) Probabilistic Knowledge Oxford: Oxford University Press.

Nagel, Jennifer (2010) "Epistemic Anxiety and Adaptive Invariantism”, Philosophical Perspectives 24(1):407-35.

Narayan, "Working Together Across Difference: Some Considerations on Emotions and Political Practice," Hypatia 3.2 (1988): 31-48.

Nelson, Mark T. (2010) “We Have No Positive Epistemic Duties”, Mind 119(473): 83-102.

Pateman, Carole (1988) The Sexual Contract, Oxford: Polity.

Plunkett, David and Sundell, Tim (2013) "Disagreement and the Semantics of Normative and Evaluative Terms", Philosophers' Imprint 13(23): 1-37

Rennison, C.M. Rape and Sexual Assault: Reporting to Police and Medical Attention, 19922000. Washington, DC: U.S. Department of Justice, Bureau of Justice Statistics, August 2002, NCJ 194530.

Rich, Adrienne (1994) Blood, Bread, and Poetry: Selected Prose 1979-1985. New York: Norton.

Ritter, Nancy (2011) The Road Ahead: Unanalyzed Evidence in Sexual Assault Cases, (NCJ Publication No. 233279), Washington, DC: U.S. Department of Justice Office of Justice Programs, National Institute of Justice (NIJ). 
Schiffer, Stephen (1996) "Contextualist Solutions to Scepticism" Proceedings of the Aristotelian Society $96(1): 317-33$.

Snyder, M., Tanke, E. D., and Berscheid, E. (1977) "Social Perception and Interpersonal Behaviour: On the Self-Fulfilling Nature of Social Stereotypes," Journal of Personality and Social Psychology, 35, 656-66.

Stanley, Jason (2005) Knowledge and Practical Interests, Oxford: Oxford University Press.

Stine, Gail C. (1976) "Skepticism, Relevant Alternatives, and Deductive Closure", Philosophical Studies 29: 249-61.

Sullivan, S. (2006) Revealing Whiteness: The Unconscious Habits of Racial Privilege. Bloomington: Indiana University Press.

Tang, Kwong-leung (1998) "Rape Law Reform in Canada: The Success and Limits of Legislation." International Journal of Offender Therapy and Comparative Criminology. (42)3

Tyler, K. A., \& Beal, M. R. (2010). "The High-Risk Environment of Homeless Young Adults: Consequences for Physical and Sexual Victimization." Violence and Victims, 25(1), 101-15.

Ullman, S. E. (2000) "Psychometric Characteristics of the Social Reactions Questionnaire: A Measure of Reactions to Sexual Assault Victims," Psychology of Women Quarterly, 24(3), $257-271$.

Ward, J. and Vann, B. (2002) "Gender-Based Violence in Refugee Settings," Lancet, 360 Suppl.: 13-14.

Weatherson, Brian (2012) "Knowledge, Bets, and Interests", In Jessica Brown \& Mikkel Gerken (eds.), Knowledge Ascriptions. Oxford University Press. pp. 75-103.

Weatherson, Brian (2017) “Interest-Relative Invariantism”, in Jonathan Ichikawa (ed.), Routledge Handbook of Epistemic Contextualism, London: Taylor \& Francis 240-53.

Wedgwood, Ralph (2008) "Contextualism about Justified Belief", Philosophers' Imprint 8(9): 120.

Wenzel, S.L., Tucker, J.S., Elliott, M.N., Marshall, G.N. and Williamson, S.L. (2004) "Physical Violence Against Impoverished Women: A Longitudinal Analysis of Risk and Protective Factors," Womens Health Issues, 14(5): 144-54.

Whisnant, Rebecca (2017) "Feminist Perspectives on Rape", The Stanford Encyclopedia of Philosophy (Fall 2017 Edition), Edward N. Zalta (ed.), URL = <https://plato.stanford.edu/archives/fall2017/entries/feminism-rape/>.

Wyatt, Gail Elizabeth (1992). "The Sociocultural Context of African American and White American Women's Rape," Journal of Social Issues. Volume 48, Issue 1, 77-91. 